\title{
A Study Of Corrosion Inhibition Of Low Carbon Steel In Washing Water Of Crude Oil Solution In The Presence Of Folic Acid
}

\author{
Ahlam M.Farhan* \\ Najah K.Nemer*
}

\author{
Naema A .Hikmat ** \\ Khaleel E.Ahmed ${ }^{* * *}$
}

Received 19, June, 2013

Accepted 23, September, 2013

\begin{abstract}
:
The corrosion behavior of low carbon steel in washing water of crude oil solution has been studied potentiostatically at five temperatures in the range (3070) ${ }^{\circ} \mathrm{C}$.The corrosion potential shifted to more negative values with increasing temperature and the corrosion current density increased with increasing temperature . Folic acid had on inhibiting effect on the corrosion of low carbon steel in washing water at a concentration $\left(5 \times 10^{-4}-5 \times 10^{-3}\right) \mathrm{mol} / \mathrm{dm}^{3}$ over the temperature range $(30$ $70)^{\circ} \mathrm{C}$.

Values of the protection efficiency were calculated from the corrosion current density .From the general results for this study, it can be seen that thermodynamic and kinetic function were also calculated $\left(\Delta \mathrm{G}, \Delta \mathrm{S}, \Delta \mathrm{H}\right.$ and $\left.\mathrm{E}_{\mathrm{a}}\right)$ to comparison these values in presence and absence of inhibitor (folic acid ) .
\end{abstract}

Key words: Carbon steel, Polarization, Washing water, Folic acid

\section{Introduction:}

Carbon steel is extensively used in different industries in the merit of its good structural properties, good mechanical workability and low cost. Dilute acid solutions are widely used in several industrial processes. However, in such aggressive media, carbon steel suffers from serious corrosion. Hence, the study of carbon steel corrosion phenomenon in acidic solution has become an important industrial and academic topic [1]

In oil production plants, many cases of extensive corrosion have occurred in production tubing, valves, and in flow lines from the wellhead to the processing equipment. The reason for this is that oil and gas from the well contain varying amounts of water, which can be precipitated as a separate phase in contact with the material surface, and that this water contains gases such as $\mathrm{CO} 2$ and possibly $\mathrm{H} 2 \mathrm{~S}$, as well as salts. In most cases of severe corrosion, $\mathrm{CO} 2$ plays a major role. The carbonic acid reacts with steel, and a layer of reaction products, to a large extent $\mathrm{FeCO} 3$, is formed on the steel surface. The deposit is cathodic relative to steel, and when small defects occur in the deposit layer, pitting corrosion is developed. Pitting is the most common cause of corrosion failures occurring in oil and gas industry production equipment. It occurs when the metal undergoing corrosion suffers metal loss at localized areas rather than over a large area or the entire surface area. The entire driving force of the corrosion reaction is concentrated at these localized areas. The corrosion rate at these areas will be many times greater

\footnotetext{
* Department of Chemistry, College of Science for Women, University of Baghdad.

** Department of Chemistry, College of Science, University of Baghdad.

***Ministry of Oil , Petroleum R \& D Center. 
than the average corrosion rate over the entire surface. Pitting is much more dangerous than uniform corrosion because the pitted area can become penetrated [2] .

Corrosion may also take place in systems for transportation or storage of oil, e.g. when the fluid for some reason has absorbed water that is precipitated afterwards. This is a known problem in various types of storage tanks. To prevent corrosion, inhibitors and (particularly in larger tanks), coatings and/or cathodic protection are used.

Inhibitors are chemicals that adsorbed on the surface of a material decreasing the material's corrosion rate, or interact with the operating environment to reduce its corrosively. Inhibitors may be introduced into the environment in which the material is operating as solutions or dispersions to form a protective film. For instance, they can be used as additives in coating products, such as surface treatments. [3]

The present work aims at evaluating the corrosion behavior of low carbon steel in Washing Water of Crude Oil Solution in the absence and the presence of folic acid .

\section{Materials and Methods:}

\section{Materials;}

1.1.Folic acid: $N$ - [4- [[(2-Amino- 1 , 4-dihydro- 4-oxo- 6- pteridinyl) methyl] amino] benzoyl] -L-glutamic acid; , more commonly known as Folic acid (fig. (2.1)) from BDH with a purity exceeding $99 \%$.

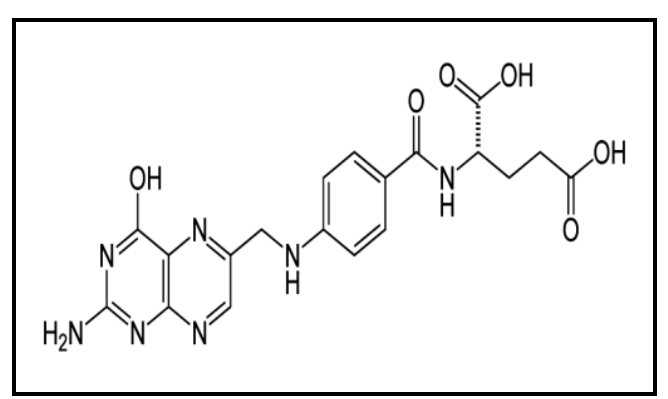

Fig :(2.1): Structure of Folic acid

1.2. Washing Water of Crude Oil Solution: This solution was obtained from Washing tanks at Buzurkan oil field in Missan governorate.

\section{Table ( 2.1) :The Specifications of Washing Water of Crude Oil}

\begin{tabular}{|l|c|}
\hline Parameter of & Results \\
\hline $\mathrm{pH}$ & 4 \\
\hline \multicolumn{1}{|c|}{ El Conductivity } & 180.600 \\
\hline Alkalinity mg/l & 220 \\
\hline Total hardness & 30450 \\
\hline Calcium hardness & 24675 \\
\hline Calcium hardness & 9870 \\
\hline Magnesium & 5775 \\
\hline Magnesium & 1386 \\
\hline Chloride mg/l & 98140 \\
\hline Sulphate $\mathrm{mg} / \mathrm{l}$ as & 2880 \\
\hline Iron $\mathrm{mg} / \mathrm{l}$ as & 0.33 \\
\hline Sulfide $\%$ as & 4.8 \\
\hline
\end{tabular}

1.3. Specimens : The specimens were cut from the same washing tank plates at Buzurkan oil field in Missan governorate.

Table ( 2.2) :Chemical composition of carbon steel

\begin{tabular}{|c|c|c|c|c|c|c|c|c|c|c|}
\hline Elements & $\mathrm{Fe} \%$ & $\mathrm{C} \%$ & $\mathrm{Si} \%$ & $\mathrm{Mn} \%$ & $\mathrm{P} \%$ & $\mathrm{~S} \%$ & $\mathrm{Cr} \%$ & $\mathrm{Ni} \%$ & $\mathrm{Al} \%$ & $\mathrm{Cu} \%$ \\
\hline Wt. \% & 98.373 & 0.187 & 0.311 & 1.03 & 0.007 & 0.012 & 0.003 & 0.029 & 0.038 & 0.002 \\
\hline
\end{tabular}


2. Instruments:

Table ( 2.3) :The instrumentation used in this study

\begin{tabular}{|c|c|c|c|}
\hline No. & Type of Device & Origin & Model \\
\hline 1 & Potentio State & Germany & M lab 200 \\
\hline 2 & $\begin{array}{l}\text { Corrosion Cell and } \\
\text { Electrode }\end{array}$ & Germany & $\begin{array}{l}1000 \mathrm{~mL} \\
\text {-Pyrex glass }\end{array}$ \\
\hline 3 & Thermo Couple & USA & \\
\hline 4 & Chiller & Germany & $\begin{array}{l}\text { HAAKE } \\
\text { OOO-3959 }\end{array}$ \\
\hline 5 & Magnetic Stirrer & China & 400 \\
\hline
\end{tabular}

\subsection{Testing Techniques}

The specimen ( low Carbon Steel )were cut into square shape with $(2 \times 2$ $\mathrm{cm}^{2}$ ) area, the open side was polished mechanically to a mirror finish. The specimen was degreased with acetone and washed distilled water, finally with ethanol and stored inside desiccators. The basic solution was washing water of crude oil obtained from Washing tanks at Buzurkan oil field in Missan governorate that used as corrosive media and folic acid was dissolved in this solution with three different concentration $(0.0005,0.001$ and 0.005 mol.. $\mathrm{dm}^{-3}$ )

The electrochemical system consists of potentio state device, corrosion cell, and electrodes. Corrosion cell made of Pyrex with (1L) capacity consists of two vessels, internal and external. Chiller device was used to make the temperature of water which flows through the external vessel constant at $(303-343) \mathrm{K}$, washing water solution of crude oil was added to the corrosion cell with stirring .Three electrodes and thermostat replaced in the internal vessel .The three electrodes consist of reference electrodes, the auxiliary electrode and the working electrode .

\section{Results and Discussions:}

\section{Polarization measurements: \\ Tafel polarization curves:}

Fig.(a) shows typical

Polarization curves for low carbon steel in Washing Water of Crude Oil
Solution and Figs .( b, c, d ) show typical Polarization curves for low carbon steel in Washing Water of Crude Oil Solution + three different concentration of folic acid (0.0005, 0.001 and 0.005 mol.dm ${ }^{-3}$ ) at five temperatures in the range $(303-343) \mathrm{K}$. The anodic and cathodic currentpotential curves were extrapolated up to their intersection at the point where corrosion current density (Icorr) and corrosion potential (Ecorr) were obtained. The electrochemical parameters Ecorr, Icorr, anodic and cathodic Tafel slopes (ba, bc) obtained from the polarization test were listed in table (3. 1),

\section{Effect of inhibitor concentration}

The corrosion protection efficiency P ( \% ) was calculated from equation:

$$
P \%=100\left[1-\frac{i_{2}}{i_{1}}\right] \quad \ldots \ldots
$$

Where $i_{1}$ and $i_{2}$ are the corrosion current densities in the absence and presence of additive in the corrosion medium respectively.

The variation of weight loss derived from the polarization curves for low carbon steel with inhibitor concentrations listed in table (3.1). It is observed that all inhibitors showed maximum inhibition efficiency $(>90 \%) \quad$ The excellent inhibition efficiency may be attributed to larger coverage of metal surface with inhibitor molecules. The corrosion rate decreases as the concentration of inhibitors increases.

\section{The Surface Coverage}

The surface coverage $(\theta)$ of the of (L.C.S.) in W.W. in presence folic acid inhibitor with different three concentration and five experimental temperatures are given in tables (3.1) could be estimated by using equation (4.2)

$$
\theta=\left[1-i_{2} / i_{1}\right] \quad \ldots . . .
$$


The adsorption of (L.C.S.) in W.W. in presence folic acid inhibitors on surface is confirmed with the usual form expressing the Langmuir isotherm - derivation from equilibrium Consideration :

$$
b=\theta /(1-\theta)
$$

Rearrangement then gives the following expression for surface coverage[4] :

$\theta=b C / 1-b C \ldots \ldots$.
$C / \theta=1 / b+C \ldots \ldots \ldots$.

Values of ( $\mathrm{C} / \theta$ ) of (L.C.S.) in W.W. in presence folic acid additive
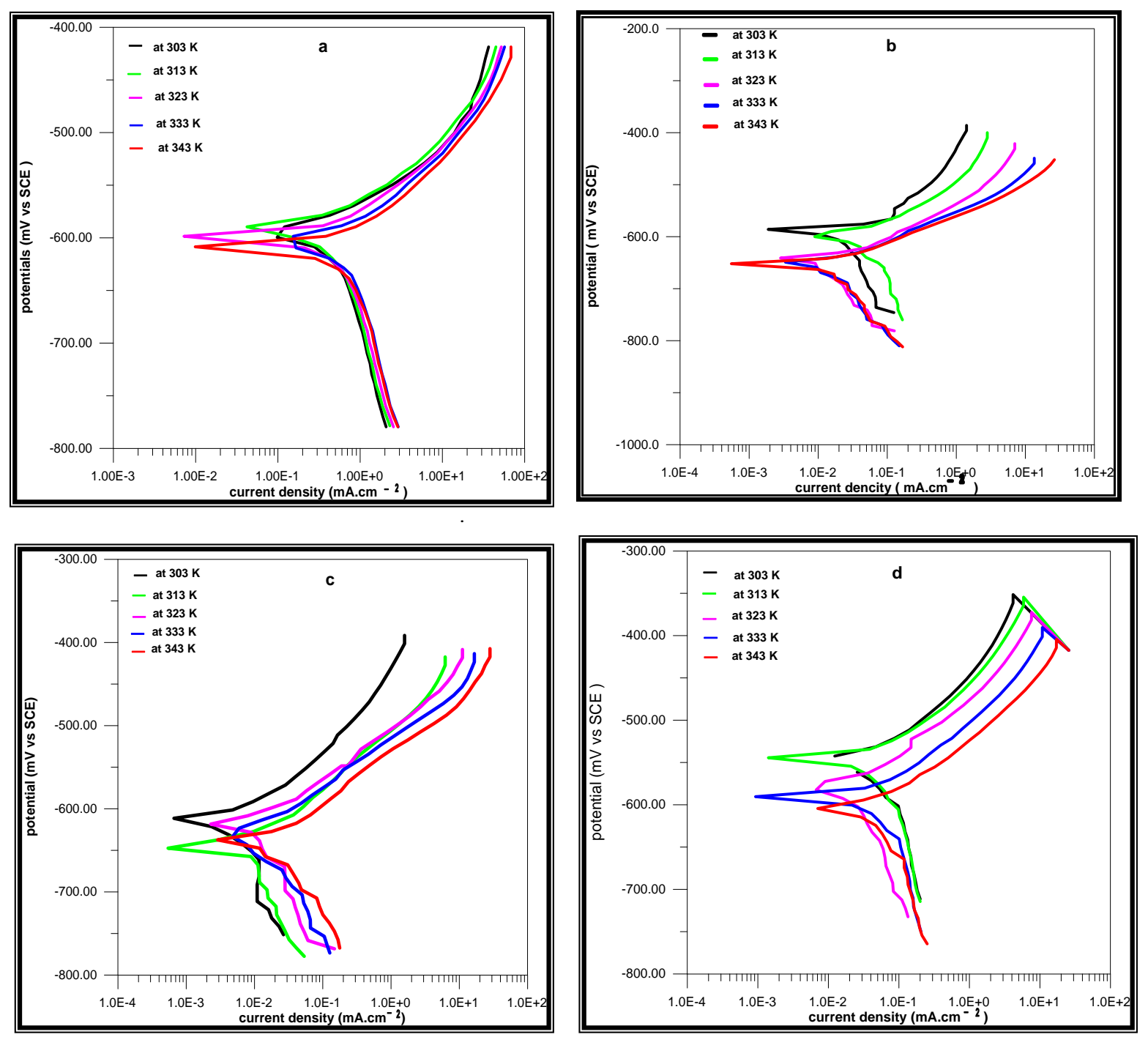

Fig.(3.1) : (a, b, c, d ): Polarization curves for low carbon steel in Washing Water of Crude Oil Solution + different concentration of folic acid ( 0.0000 $, 0.0005,0.0010$ and $0.0050 \mathrm{~mol}^{\circ} \mathrm{dm}^{-3}$ ) respectively, at five temperatures. 


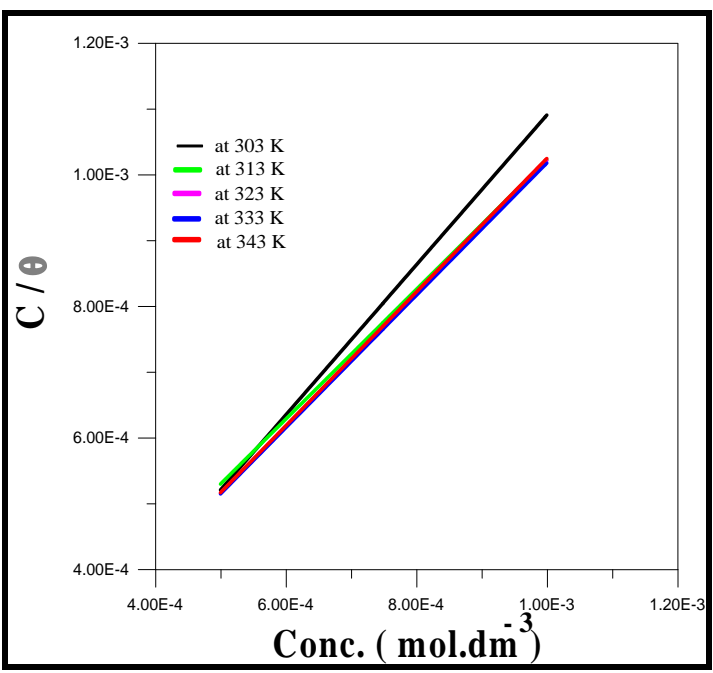

Fig.(3.2):A plot of $\mathrm{C} / \boldsymbol{\theta}$ values against the corresponding values of Conc of folic acid at different temperature in the range $303-343 K$.

Table(3.1) : Values of corrosion potentials $\mathbf{E}_{\text {corr }}<$ corrosion current densities $\mathbf{i}_{\text {corr }}$, cathodic and anodic Tafel slopes $b_{c}$ and $b_{a}$, weight loss 'penetration loss, Corrosion protection efficiency $P \%$ and Surface Coverage ( $\theta$ ) for (L.C.S.) in W.W. solution in presence of three concentration of Folic acid at five temperatures

\begin{tabular}{|c|c|c|c|c|c|c|c|c|c|}
\hline \\
\hline 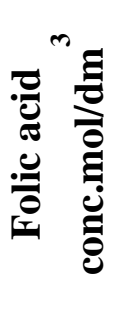 & $\frac{\theta}{\theta}$ & $\sum_{\substack{5 \\
0 \\
10}}$ & & 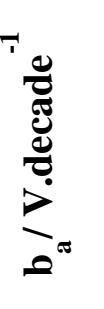 & 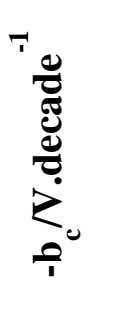 & 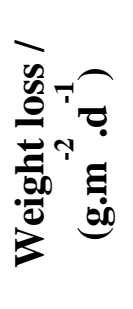 & 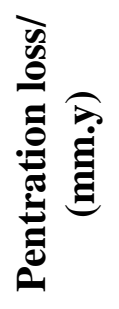 & $\begin{array}{l}0 \\
a\end{array}$ & 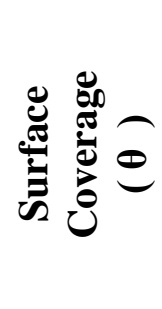 \\
\hline \multirow[t]{5}{*}{0} & 303 & 0.600 & 313.7 & 57.0 & 124.1 & 78.4 & 3.64 & - & $=$ \\
\hline & 313 & 0.590 & 386.0 & 55.5 & 198.9 & 96.5 & 4.48 & - & $=$ \\
\hline & 323 & 0.601 & 471.0 & 65.4 & 202.1 & 118.0 & 5.47 & - & $=$ \\
\hline & 333 & 0.603 & 569.0 & 65.5 & 211.0 & 142.0 & 6.60 & - & $=$ \\
\hline & 343 & 0.610 & 579.9 & 65.8 & 203.0 & 414.5 & 6.73 & - & $=$ \\
\hline \multirow[t]{5}{*}{0.0005} & 303 & 0.588 & 12.33 & 50.1 & 103.8 & 3.08 & 0.14 & 96.1 & 0.961 \\
\hline & 313 & 0.597 & 21.42 & 50.5 & 101.1 & 5.35 & 0.25 & 94.5 & 0.945 \\
\hline & 323 & 0.641 & 13.31 & 40.5 & 222.6 & 3.33 & 0.15 & 97.2 & 0.971 \\
\hline & 333 & 0.651 & 15.29 & 51.6 & 185.8 & 3.82 & 018 & 97.3 & 0.973 \\
\hline & 343 & 0.679 & 18.07 & 63.1 & 138.2 & 4.52 & 0.21 & 96.9 & 0.969 \\
\hline \multirow[t]{5}{*}{0.001} & 303 & 0.611 & 6.06 & 60.8 & 267.6 & 1.51 & 0.07 & 98.1 & 0.981 \\
\hline & 313 & 0.647 & 8.35 & 64.3 & 194.8 & 2.09 & 0.09 & 97.8 & 0.978 \\
\hline & 323 & 0.619 & 9.81 & 53.0 & 164.4 & 2.45 & 0.11 & 97.9 & 0.979 \\
\hline & 333 & 0.632 & 9.62 & 54.9 & 111.0 & 2.41 & 0.11 & 98.3 & 0.983 \\
\hline & 343 & 0.637 & 14.03 & 56.6 & 99.2 & 3.51 & 0.16 & 97.6 & 0.976 \\
\hline \multirow[t]{5}{*}{0.005} & 303 & 0.552 & 22.66 & 52.7 & 80.8 & 5.67 & 0.26 & 92.8 & 0.928 \\
\hline & 313 & 0.544 & 25.59 & 41.7 & 110.2 & 6.40 & 0.30 & 93.4 & 0.934 \\
\hline & 323 & 0.582 & 28.71 & 70.6 & 232.1 & 7.18 & 0.33 & 93.9 & 0.939 \\
\hline & 333 & 0.590 & 32.18 & 55.6 & 117.6 & 8.05 & 0.37 & 94.3 & 0.943 \\
\hline & 343 & 0.603 & 34.53 & 48.7 & 132.5 & 8.63 & 0.40 & 94.1 & 0.940 \\
\hline
\end{tabular}




\subsection{Thermodynamic of Corrosion}

Thermodynamic laws tell us that there is a strong tendency for high energy state in a system to transform into low energy state. It is this tendency of metals to recombine with components of the environment that leads to the phenomenon known as corrosion[5] The free - energy change accompanying an electrochemical reaction can be calculated by the following equation [6] .

$$
\Delta G=-n F E
$$

Where $\Delta G$ is the free - energy change, $n$ is the number of electrons involved in the reaction, $F$ is the Faraday constant, and $E$ equals the cell potential $\left(\mathrm{E}=\mathrm{E}_{\text {corr }}\right)$. From the value of $\Delta G$ at several temperatures, the change in the entropy $(\Delta S)$ of corrosion process could be derived according to the well - known thermodynamic relation :

$$
\Delta S=-\frac{d(\Delta G)}{d T}
$$

Values of $\Delta G$ are usually plotted against temperature (T); thus at any temperature the value of $-d(\Delta G) / d T=\Delta S$ which corresponds to the slope of the $(-\Delta G)$ versus $(\mathrm{T})$ plot at that temperature, as shown in fig. (3.3).

Utilizing the values of $\Delta \mathrm{G}$ and $\Delta \mathrm{S}$, it was possible to calculate the values of the change in the enthalpy $\Delta \mathrm{H}$ for the corrosion process from the relation:

$$
\Delta G=\Delta H-T \Delta S \quad \ldots \ldots \quad(3.8)
$$

The thermodynamic quantities $\Delta \mathrm{G}, \Delta \mathrm{S}$ and $\Delta \mathrm{H}$ for low carbon steel. corrosion in Washing Water of Crude Oil Solution with different concentration of folic acid at five temperatures in the range $303-343 \mathrm{~K}$ are given in the table (3. 2 ). The results in the tables indicate negative values of $\Delta \mathrm{G}$ that mean, these reaction are occurring spontaneously. Values of the enthalpy of corrosion $(\Delta \mathrm{H})$ reflect the enthalpy changes associated with the corrosion reaction and ranged from negative to positive values indicating exothermic or endothermic nature of corrosion reaction. negative values of $(\Delta \mathrm{H})$ indicating a stronger bonding of the metal ions, resulting from electrode corrosion, with the species that are present in the corrosion medium as compared with the bonding of the metal atoms in the crystal lattice of the solid electrode.

Values of $(\Delta S)$ were positive or negative depending on the positive or negative dependencies of $(\Delta G)$ values on temperatures. The positive values of $\Delta \mathrm{S}$ show an increase random at solid /solution interface during the adsorption process, which suggest that metal ions replace some water molecules from solution previously adsorbed on the surface of the adsorbent. These displaced molecules gain more translation entropy than is lost by the adsorbate ions thus allowing the prevalence of randomness in the system.

\section{Kinetic Of Corrosion:}

The rate of corrosion' as expressed by the corrosion current density $\left(i_{\text {corr }}\right)$ increased with the rise of temperature follow Arrhenius equation,

$$
\left.i_{\text {corr }}=A \exp \left(-E_{a} / R T\right) \ldots \ldots \ldots \text { ( } 3.9\right)
$$

Where $A$ and $E_{a}$ are the preexponential factor and energy of activation of the corrosion process respectively. Values of $E_{a}$ were derived from the slopes of the (log $\left.i_{\text {corr }}\right)$ versus $(1 / \mathrm{T})$ linear plots as while those of (A) were obtained from the intercepts of the plots at $(1 / \mathrm{T}=\mathrm{zero})$; values of $(\mathrm{A})$, expressed in term of (Amper $\mathrm{cm}^{-2}$ ), then have been converted into (molecules per $\mathrm{cm}^{2}$ per second) ${ }^{(95)} 153$ A ). Table (3.3) appears values of the activation energy $\left(E_{a}\right), \log A$ and preexponential factors (A), for (L.C.S.) in (W.W.) in the absence and presence of 
three concentrations of folic acid as shown in fig (3.4) .

Generally, the values of $\left(E_{a}\right)$ were lower for inhibited solutions than that for uninhibited solutions .

Radovici classifies the inhibitors into three groups according to the temperature effects[7] .

1. Inhibitors whose $(P \%)$ decreases with temperature increase. The value of the apparent activation energy $\mathrm{Ea}$ found is greater than that in the uninhibited solution.

2. Inhibitors whose $(P \%)$ does not change with temperature variation. The apparent activation energy does not change with the presence or absence inhibitors'.

3. Inhibitors in whose presence the $(\mathrm{P} \%)$ increases with temperature increase while the value of Ea for the corrosion process is smaller than that obtained in the uninhibited solution.

This is an indication, for a specific type of adsorption of the inhibitors. the corrosion process taking place in the presence of powerful inhibitors is characterized by an activation energy whose value is smaller than that of the uninhibited process. The lower value of the activation energy of the process in an inhibitor's presence when compared to that in its absence is attributed to its chemisorptions, while the opposite is the case with physical adsorption[7].

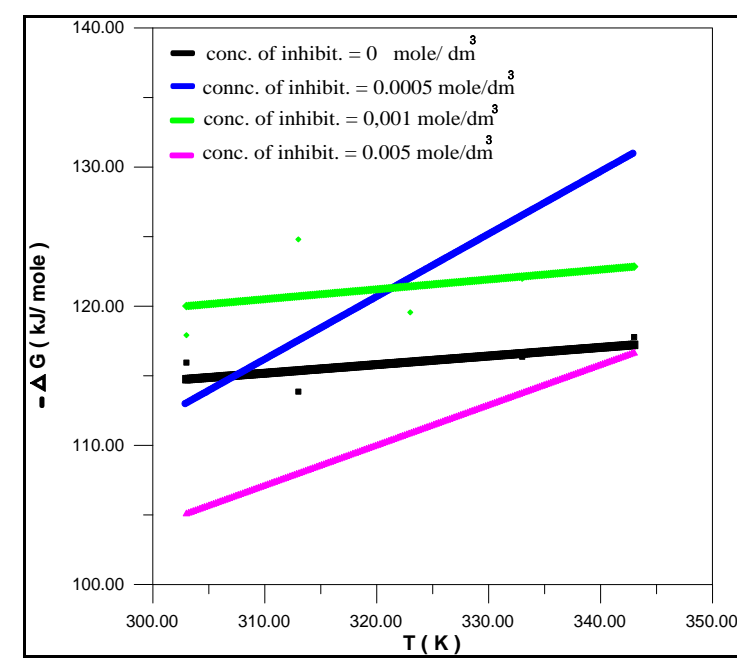

Fig.(3.3): The variation of the $(-\Delta G)$ with temperature ( $T$ ) for low carbon steel in Washing Water of Crude Oil Solution in the absence and presence of folic acid 4 at five temperatures.

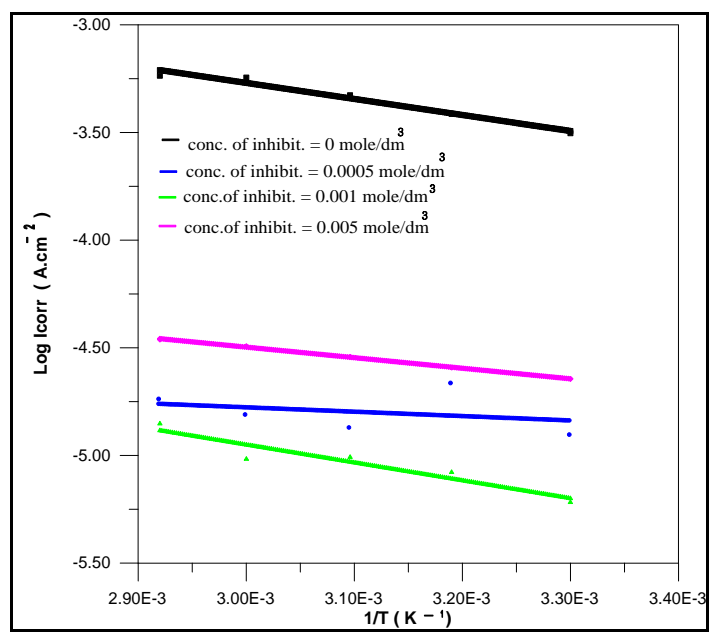

Fig.(3.4) :Arrhenius plots, relating $\left(\log i_{\text {corr }}\right)$ values to $(1 / T)$ for low carbon steel in Washing Water of Crude Oil Solution in the absence and presence of folic $\mathrm{aci}_{4}$ at five temperatures. 
Table (3.2) : Values of the thermodynamic quantities and activation energy $\left(\mathbf{E}_{\mathbf{a}}\right)$, for low carbon steel in Washing Water of Crude Oil Solution in the absence and presence of folic acid 4 at five temperatures.

\begin{tabular}{|c|c|c|c|c|}
\hline $\begin{array}{c}\text { Folic acid } \\
\text { conc.mol/dm }\end{array}$ & $\mathbf{T} /(\mathbf{K})$ & $\begin{array}{c}-\Delta G /{ }^{-1} \\
\text { kJ.mol }\end{array}$ & $\Delta \mathrm{S} / \mathbf{1}_{\mathbf{K}}^{\mathrm{J} . \mathrm{mol}}$ & $\Delta H /$ kJ.mol $^{-1}$ \\
\hline \multirow{5}{*}{ then } & 303 & 115.95 & \multirow{5}{*}{61.75} & -97.24 \\
\hline & 313 & 113.86 & & -94.54 \\
\hline & 323 & 115.97 & & -96.02 \\
\hline & 333 & 116.37 & & -95.80 \\
\hline & 343 & 117.78 & & -97.38 \\
\hline \multirow{5}{*}{0.0005} & 303 & 1113.66 & \multirow{5}{*}{449.50} & 22.54 \\
\hline & 313 & 115.39 & & 25.31 \\
\hline & 323 & 123.86 & & 21.33 \\
\hline & 333 & 125.58 & & 24.11 \\
\hline & 343 & 131.04 & & 23.14 \\
\hline \multirow{5}{*}{0.001} & 303 & 117.91 & \multirow{5}{*}{70.83} & -96.46 \\
\hline & 313 & 124.81 & & -102.64 \\
\hline & 323 & 119.56 & & -96.68 \\
\hline & 333 & 121.97 & & -97.38 \\
\hline & 343 & 122.88 & & -98.58 \\
\hline \multirow{5}{*}{0.005} & 303 & 106.45 & \multirow{5}{*}{288.90} & -18.92 \\
\hline & 313 & 105.02 & & -14.60 \\
\hline & 323 & 112.40 & & -19.08 \\
\hline & 333 & 113.92 & & -17.72 \\
\hline & 343 & 116.45 & & -17.36 \\
\hline
\end{tabular}

Table (3.3): Values of activation energy $\left(E_{a}\right)$ and pre- exponential factors $(A)$ of (L.C.S.) in( W.W.) in the absence and presence of three concentrations of Folic acid

\begin{tabular}{|c|c|c|c|}
\hline $\begin{array}{c}\text { Conc. } \\
\text { mol.dm }^{-3}\end{array}$ & $\begin{array}{c}E_{a} \\
\left(\text { kJ.mol }^{-1}\right)\end{array}$ & Log A & $\begin{array}{c}A \\
\left(\text { molecules.cm }^{-2} . s^{-1}\right)\end{array}$ \\
\hline 0.000 & 14.26 & -1.04 & $5.758 \times 10^{17}$ \\
\hline 0.0005 & 3.89 & -4.17 & $4.200 \times 10^{14}$ \\
\hline 0.001 & 15.88 & -2.46 & $2.157 \times 10^{17}$ \\
\hline 0.005 & 9.39 & -3.03 & $5.889 \times 10^{15}$ \\
\hline
\end{tabular}

\section{Conclusions:}

1-The efficiencies of the folic acid in Washing Water of Crude Oil Solution tested on low carbon steel as corrosion inhibitor is dependent on concentration and temperature.

The best efficiency was in concentration of folic acid $=0.001$ mol.dm ${ }^{-3}$
2- The efficiencies in three different concentration of folic acid were increased at high temperature

3- The high efficiencies as a result of the large molecular Weight of folic acid formed a complex and chelate with iron, which prevented iron from further oxidation

4- The values of $\left(E_{a}\right)$ were lower for inhibited solutions than that for uninhibited solutions. . 


\section{References:}

1- Xiumei Wanga, Huaiyu Yang and Fuhui Wang. 2012. Inhibition performance of a gemini surfactant and its co-adsorption effect with halides on mild steel in $0.25 \mathrm{M}$ $\mathrm{H} 2 \mathrm{SO} 4$ solution, Corrosion Science, .55: .145-152.

2- Einar Bardal.2004.Corrosion and protection. - (Engineering materials and Processes), Springer-Verlag London Limited, pp .212.

3- H.A.Abbas. 2012. Corrosion and Corrosion Inhibition Study of Galvanized Steel in Salty Acidic and Basic Media ,M.Sc. Thesis ,College of Science ,Baghdad University .

4 - Xiaoxia Sheng, Yen-Peng Ting, and Simo Olavi Pehkonen . 2007.
Evaluation of an Organic Corrosion Inhibitor on Abiotic Corrosion and Microbiologically Influenced Corrosion of Mild Steel, Ind. Eng. Chem. Res., 46:7117-7125.

5- K .R. Tretherwey and J .chamberlain. Corrosion for Science and Engineerihg, second ed.,(Addision Wesley Longman L.td.), 1996.

6- I.I.Sherir, 1976. Corrosion, Metal/ Environment Reaction, second ed,.1:.4:12.

7 - Y. K. Al-Haydari, J. M. Saleh and M. H. Matloob, J. 1985. Adsorption and Decomposition of Hydrazine on Metal Films of Iron, Nickel, and Copper, Phys. Chem., 89, 3286 3395

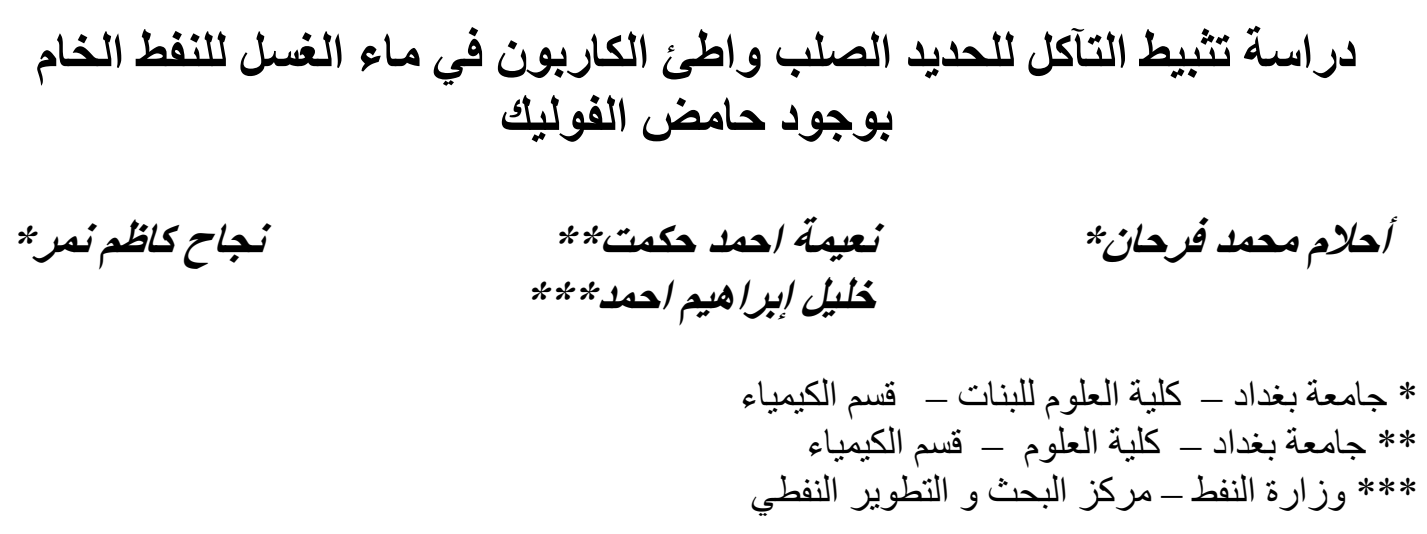

الخلاصة: نم في هذا البحث دراسة سلوك التآكل لسبيكة الفولاذ واطئ الكاربون بمحلول ماء الغسيل للنفط الخام

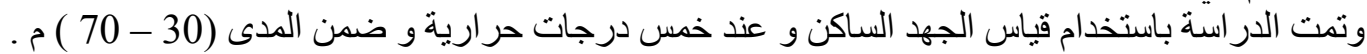

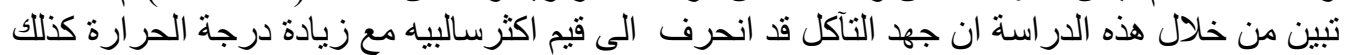

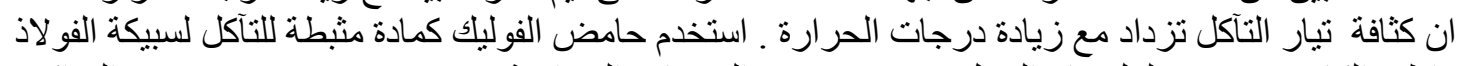

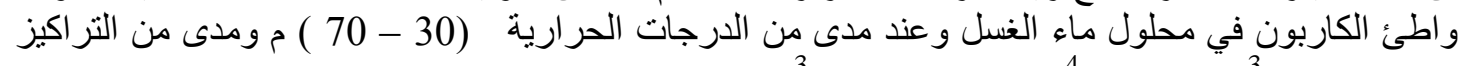

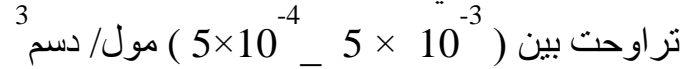

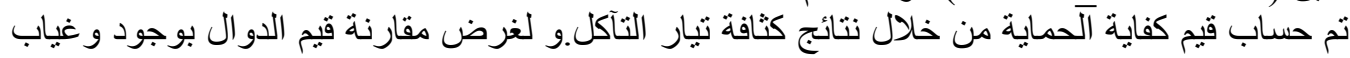

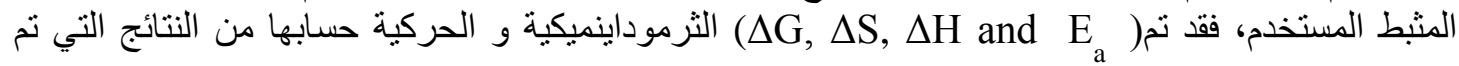
الحصول عليها في هذه الدراسة. 